\title{
Socio-cultural transformation as a systemic phenomenon in cultural dynamics
}

\author{
Aleksey Tarasov ${ }^{1 *}$, Dmitry Belyaev ${ }^{1}$ and Inga Pogorelova ${ }^{1}$ \\ ${ }^{1}$ Lipetsk State Pedagogical P. Semenov-Tyan-Shansky University, 398020, Lipetsk, Russia
}

\begin{abstract}
The paper reveals peculiarities of transition periods in cultural dynamics. These processes are analysed by using the example of the continuum of European (as of the 19th c. - Euro-Atlantic) culture. The end of transition periods which are defined by the concept of "sociocultural transformation" marks the beginning of progressive evolution of culture - the stage determined by the notion of "culture system". The study singles out four stages of socio-cultural transformations in the continuum of European culture (late Hellenism, the Renaissance, the avant-garde, and postmodernity) as well as four culture systems (ancient, mediaeval, neoEuropean, and modern). The paper concludes that characterising sociocultural transformations makes it possible to determine a concrete set of their features. These features are defined by the concept of "culturally dominant characteristics". Various stages of socio-cultural transformations generally display the same set of such characteristics, the latter manifesting themselves with varying degrees of intensity, whereas the set of culturally dominant characteristics reflecting the essence of culture systems is different. The research resulted in singling out the following culturally dominant characteristics of socio-cultural transformations: relativism, pluralism, eclecticism, skepticism, gamification, as well as a break with the preceding cultural tradition. The research raises the problem of extending the application of the aforementioned regularities to the cultural dynamics of other civilisations.
\end{abstract}

\section{Introduction}

The study of transition periods in cultural dynamics has been generating much interest among scholars in the last two decades, which is confirmed by numerous scientific conferences (Gumanitaristika, 2017, 2018) and research papers on this subject (Perekhodnyye epokhi, 2003). Such periods are characterised by establishing a new type of culturedness of an anthropogenic character in accordance with the new conditions and are treated in this paper as socio-cultural transformations (Tarasov, 2016).

The research presented in the paper explores peculiarities of socio-cultural transformations on the example of the continuum of European culture, which resulted in singling out 4 stages: late Hellenism, the Renaissance, the avant-garde, and postmodernity.

\footnotetext{
* Corresponding author: alexei1997@yandex.ru
} 
The stages established in the process of these socio-cultural transformations are defined as culture systems, to which refer antiquity, the Middle Ages, the modern era, and the contemporary period. Based on the aforesaid transition periods, the dynamics of European (Euro-Atlantic) culture might be presented as follows:

\begin{tabular}{|c|c|l|}
\hline $\begin{array}{c}\text { Stage of socio- } \\
\text { cultural } \\
\text { transformation }\end{array}$ & Timespan & \multicolumn{1}{|c|}{$\begin{array}{c}\text { Features of } \\
\text { socio-cultural transformation }\end{array}$} \\
\hline late Hellenism & III - V cc. & $\begin{array}{l}\text { Reflected the transition from the } \\
\text { antique to the mediaeval culture } \\
\text { system }\end{array}$ \\
\hline the Renaissance & XV-early XVII cc. & $\begin{array}{l}\text { Reflected the transition from the } \\
\text { mediaeval to the neo-European } \\
\text { culture system }\end{array}$ \\
\hline the avant-garde & $\begin{array}{c}\text { XIX- early XX cc. } \\
\text { the last third of }\end{array}$ & $\begin{array}{l}\text { Reflected the transition from the } \\
\text { neo-European to the modern culture } \\
\text { system }\end{array}$ \\
\hline postmodernity & $\begin{array}{c}\text { the last quarter of } \\
\text { XX - early XXI cc. }\end{array}$ & $\begin{array}{l}\text { Reflected the transition from the } \\
\text { modern to the post-modern culture } \\
\text { system }\end{array}$ \\
\hline
\end{tabular}

\section{Method}

The specific nature of transition periods stipulated the choice of research methods. The logic of studying socio-cultural transformations as transitional stages extending over fairly large periods of time and possessing a number of qualitative characteristics implies the use of the interdisciplinary approach. The method of philosophical interpretation employed in the study as the major method allowed revealing the ontological basis of socio-cultural transformations.

The particularities of the development of art, science, religion, and philosophy during socio-cultural transformations were singled out with the help of the comparative and structural-functional analyses. The essence of the processes in question was investigated with the aid of such methods as abstraction, typologisation, rising from the abstract to the concrete, analysis and synthesis. The same methods enabled the authors to determine the development prospects of transition periods. The temporal method was used for exposing cause-and-effect relationships. The whole set of the aforementioned methods allowed revealing the essence of socio-cultural transformations as transition periods in cultural dynamics.

\section{Results}

The approach to the dynamics of European (Euro-Atlantic) culture presented in the paper combines the linear model with elements of the synergetic model. The linear (or evolutionary) model implies considering cultural changes from the standpoint of the general set idea of social progress. This form of dynamics is characterised by the rectilinear orientation of the cultural process as society goes through the corresponding stages defined in the research as 'culture systems'. The transition between these stages towards new levels of culturedness of an anthropogenic character is effected through socio-cultural transformations. 
In light of this view on cultural dynamics, the spiritual life of a society is understood as development from a simple state to a more complex one involving a continuous sequential flow of time periods, in which each time period comes out more advanced than its predecessor.

Each period of a culture system is characterised by progressive development and a set of certain features that determine its evolution throughout the whole continuum of its existence. Defined as 'culturally dominant characteristics', these features act as the basic cultural paradigms which manifest themselves in most peculiar ways in all spheres of spiritual life and throughout the given stage of a culture system.

It is possible to identify four culture systems in the dynamics of European culture: antique, mediaeval, neo-European, and contemporary. Each of them is characterised by stable development conditioned by the corresponding culturally dominant features which give it meaning and consistency.

During each stage of progressive development, changes in all spheres of culture occur constantly albeit with varying degrees of intensity, therefore it would be a mistake to describe stages of culture systems as static. These changes occur within the anthropogenic cultural framework characteristic of the corresponding period of progressive development. For instance, while investigating processes within the dynamics of European culture through the prism of socio-cultural transformations, it was established that one of the culturally dominant features of antiquity is agonality. This feature implies the principle of competition permeating all spheres of life. The principle of agonality applied both to a concrete personality and whole social groups or city-states. The spirit of competition was ultimately aimed at achieving the best possible result and maximal efficiency in a particular case. Winning in that competition was rewarded with social esteem and respect. Agonality can be referred to culturally dominant characteristics of antiquity on account of its being one of the fundamental ideological lines along which the society and culture of that time developed. It manifested itself in all areas of spiritual life in a peculiar way. Thus, in philosophy, it translated into the ideological clash between various schools of thought, which explains the existence of numerous and frequently held debates between those schools. In the art of Ancient Greece there are multiple examples of scenes of athletic competitions (in vase painting, for instance). In science, agonality was evident in the desire to be the first to make a scientific discovery and present it to the scientific community. In other words, the principle of competition was one of the ideological foundations determining the life of society in antiquity.

Many researchers of this period of European cultural dynamics point out that due to the antique culture system, the principle of agonality had such a powerful impact on the spirit of the time that it laid the foundation for its manifestation during the subsequent stages (Shtaerman, 1975; Kroeber, 1960). For instance, it is indirectly displayed in the principle of respect for human rights and dignity, or in the idea of equality before the law. Yet, even despite this impact, one couldn't claim agonality to be a culturally dominant characteristic of the contemporary period in the development of the spiritual life of European (EuroAtlantic) civilisation, let alone of the mediaeval culture system, which followed antiquity.

Thus, agonality characterises a certain stage in the cultural continuum without rigorously applying to European spiritual life on the whole. It is possible to make similar conclusions regarding each culture system and each culturally dominant characteristic of the corresponding period. For example, if theocentricism defined the world view of mediaeval Europe, it is erroneous to argue that it influenced the neo-European or any other subsequent period.

All spheres of mediaeval spiritual life reflected the idea of God as the first cause and foundation of existence. The idea figured prominently in the art of the period. Moreover, due to this basic principle of the mediaeval world-view new art forms (like icon painting) 
emerged; and architecture reached new heights. Theocentricism also had a curious effect on the development of science: the fact that mediaeval European science had no remarkable achievements by comparison with oriental cultures may be largely conditioned by the primacy of faith over reason. Nevertheless, it is erroneous to apply this meaning of theocentricism to the antique (let alone contemporary) culture system.

So, it is due to the existence of some culturally dominant characteristics that the progressive development of a certain culture system is determined. They are specific to each system, are realised in all areas of spiritual life, and enable one to distinguish between different culture systems fairly accurately.

The analysis of transition periods in cultural dynamics (in contrast to periods of progressive development) revealed that in general, the set of the aforementioned features turns out to be the same irrespective of the time period. To such culturally dominant characteristics refer relativism, pluralism, skepticism, eclecticism, gamification, and a break with the preceding cultural tradition.

All of these features invariably manifest themselves during different stages of sociocultural transformations, albeit with varying degrees of intensity. The peculiarity of culturally dominant characteristics of transition periods is that they contribute to the annihilation of the ones that reflect the essence of the previous culture system and pave the way for the ones that will establish the next system. The fact that the set of such characteristics for the periods of socio-cultural transformations is more or less permanent, and that it is different for the stages of culture systems makes it possible to characterise transition periods as a regular and systemic phenomenon in the dynamics of culture. The phenomenon is necessary for bringing culture to a new level and making it acquire an anthropogenic character, the latter undergoing changes as society develops.

Such periods witness a qualitative change in the spiritual life of a society, elimination of culturally dominant characteristics of the previous period, and the establishment of the attributive characteristics of the next. By comparison with stages of culture systems, which are evolutionary by nature, the establishment of a socio-cultural transformation is a fairly fast process. There is no doubt that the duration of this process varies with different stages of the cultural continuum. Yet, the law of historical time acceleration holds true both for progressive stages and transition periods. For instance, if late Hellenism spans several centuries, the avant-garde as a socio-cultural transformation barely lasts for half a century. At the same time, despite this difference, according to the law of historical time acceleration, they are chronologically proportionate to the preceding stages of culture systems. In particular, the Middle Ages span approximately ten centuries, the Renaissance, which followed it, lasted for about two and a half centuries (as a pan-European phenomenon); further on, the neo-European culture system existed for less than three centuries, whereas the avant-garde, which succeeded it, only lasted about half a century. Thus, each successive culture system is chronologically shorter than its predecessor, as well as each successive socio-cultural transformation is far shorter than the one preceding it.

Another peculiarity of socio-cultural transformations as a systemic phenomenon in cultural dynamics is rooted in its essence and manifests itself in the fact that any qualitative change in the spiritual life of a society can only be effected due to a transition period.

Various changes occur in socio-cultural evolution on a constant basis. Their existence allowed identifying among them structural and systemic phenomena which were eventually confirmed in the process of exploring the continuum of European culture. Structural phenomena are realised within the framework of a culture system proper and do not entail any systemic changes, i.e. changes bringing a society to a new stage of its development. One such change, for example, is the transition from classical antiquity to the Hellenistic period, or less significant (continuum-wise) phenomena like art styles succession. Therefore structural changes are distinguished by their manifestation in one sphere of 
culture or by their influence on each cultural sphere, but within and by means of the culturally dominant characteristics of the same culture system.

Unlike structural changes, systemic changes first of all always apply to all forms of culture and secondly, act comprehensively, eliminating old culturally dominant characteristics and establishing new ones, which are very often opposite to their predecessors.

The aforementioned observation made while exploring the dynamics of European culture allowed singing out two types of changes: crisis (which reflects the structural essence of the process), and socio-cultural transformation (reflecting the systemic essence of the process).

The process of progressing towards a new quality in each cultural sphere is unique and depends on the peculiarities of the cultural sphere as well as on the conditions in which it develops. Thus, changes in the religious sphere during the socio-cultural transformation after the Middle Ages took effect much faster than those that occurred during the transition from the neo-European culture system to the contemporary one.

In each area of culture, the transition to a new quality happens in a specific way that is not universal for the other areas. In turn, this feature impacts on the intensity of the ongoing changes. In some cultural spheres, the development is quite rapid, in others, on the contrary, it is far less so. This is determined both by the time period, when earlier socio-cultural transformations are characterised by a longer duration (and vice versa) as well as by the specificity of each sphere (for instance, viewed in this light, religion seems to be rather conservative, whereas science - far more dynamic).

With drastic changes, old culturally dominant characteristics are eliminated rather quickly, while with gradual ones -

more slowly. In the latter case, the old features may exist for a long time. Yet, eventually an overall transformation takes place, i.e. a new culture system with its inherent culturally dominant characteristics is established.

Another problem arising in the context of exploring socio-cultural transformations as a systemic phenomenon in the spiritual life of a society in light of the linear model is that of the essence of progress in culture. On the whole, progress implies a transition from the less perfect to the more perfect (Kul'turologija, 2009). Progress manifests itself in the quantitative and qualitative improvement of a society's life. The analysis of the development of European (Euro-Atlantic) civilisation shows that the civilisation in question, acting as a trigger for the global historical process for a long time, laid the foundations for this understanding of the essence of progress. What is of great importance here is not only a quantitative growth (of knowledge, for instance), but also the qualitative component manifesting itself, among other things, in breakthrough scientific discoveries which contributed to the appearance of new directions in scientific research.

Therefore raising the level of organisation of culture might serve as an ever important universal criterion for cultural progress. If in the course of cultural dynamics the constituent elements of culture grow in number, the structures which connect these elements become more complex, increasing the number of interconnections and interactions, and if the set of functions (i.e. actions performed by a socio-cultural complex, thus ensuring greater stability and further development as compared with the previous culture system) is enlarged, the entire set of changes in question can be characterised as progress in culture.

The aforementioned set of features does not necessarily mean that it is characteristic of all spheres of culture. As it has already been mentioned, changes in religious life are not as prominent as, for example, in science.

One should not ignore the opposite tendency when progressive development of one form of culture does not entail cultural progress on the whole. For instance, if a cultural 
complex becomes generally more sophisticated, it does not exclude the possibility of some of its functions or constituent elements becoming simpler or even deteriorating.

As the study of causes of socio-cultural transformations showed, they are conditioned by socio-economic factors (Tarasov, 2018). Nevertheless, apart from these external conditions there are also immanent ones. Their nature can be understood not only by means of considering the dynamics of European culture through the prism of socio-cultural transformations, but also with the aid of the synergetic approach.

In light of this approach, any system, including culture, undergoes two stages. The first one is characterised by gradual development with quite predictable results. In our case, it corresponds to the stage of a culture system. The second is determined by the notion of a leap which gives the whole system a new quality. In the context of this study, it corresponds to the stage of a socio-cultural transformation. From the point of view of synergetics, the results of development during the second stage are hard to predict as at such moments the whole system faces the necessity to choose one of the many existing options. The choice is made randomly, and is determined by a concurrence of circumstances at a given point in time. Interestingly, after the choice or a transition to a new quality has been made, the system will not be able to return to its previous state, which in our case corresponds to the establishment of the stage of a culture-system.

\section{Discussion}

The principles of the synergetic model of cultural dynamics presented in the paper may well be applied to the problem of the role of immanent factors in the development of spiritual life. These principles allow considering culture not merely as a linear process but also as the sum total of gradual and intense development. In this process, along with external impacts, the dynamics of spiritual life are also determined by internal (immanent) factors, such as, for example, the author's subjective intent, personal outlook, and various experiments in different spheres of culture (Romah, 2007, 2013). If society approves of the results of these phenomena, they can establish themselves in culture under the influence of culturally dominant characteristics of a socio-cultural transformation, and get a certain status thereby marking a new stage of a culture-system.

Thus, the analysis of European cultural dynamics shows that processes taking place within their framework may be characterised by means of the linear model of development with some elements of the synergetic model. This combination makes it possible to reveal the essence of the ongoing changes in light of external and internal factors of cultural dynamics more precisely.

The study of socio-cultural transformations in the continuum of European culture demonstrates that the processes of spiritual dynamics in this region are unique in that chronologically they do not coincide with transition periods in the cultures of other civilisations. It confirms the idea accepted by the modern theory and philosophy of culture that it is rather difficult to identify universal laws of development applicable to every region of the world. This, in turn, enables the researcher to renounce the principle of a rigid mechanistic determinism, which arose from evolutionary anthropology, and to reveal the uniqueness of each culture. At the same time, the identification and analysis of culturally dominant characteristics of transition stages in the dynamics of oriental (or any other) cultures irrespective of their timing has a great potential in terms of finding out universal regularities reflecting the essence of socio-cultural transformations on the whole.

\section{References}


1. Humanitarian studies in the context of the modern-day socio-cultural transformation, Proceedings of the VII All-Russian scientific conference. 17-18 Nov., 2017. Lipetsk, Lipetsk State Pedagogical P. Semenov-Tyan-Shansky University, 126 (2017)

2. Humanitarian studies in the context of the modern-day socio-cultural transformation, Proceedings of the VIII All-Russian scientific conference with international participation. 9-10 Nov., 2018, Lipetsk, Lipetsk State Pedagogical P. Semenov-TyanShansky University, 204 (2018)

3. Culturology, dictionary and reference-book (Feniks, Rostov-on-Don, 2009)

4. Transitional epochs in a social dimension, Ed. V.L. Malkov (Institute of World Hisotry, Nauka, Moscow, 2003)

5. O.V. Romah, Activity as a way of cultural development, Culturology analytics, 8, 119127 (2007)

6. O.V. Romah, Numerous interpretations of the culture concept, Culturology analytics, 26, 40-44 (2013)

7. E.M. Shtaerman, The crisis of ancient culture (Nauka, Moscow, 1975)

8. A. Kroeber, Style and Civilizations (Cornell University Press, N.Y., 1960)

9. A.N. Tarasov, A Philosophical Analysis of Renaissance Culture as a Sociocultural Transformation in the Continuum of European Culture, International Journal of Civil Engineering and Technology, 9(11), 2569-2577 (2018)

10. A.N. Tarasov, Theoretical-methodological Bases of the "Sociocultural Transformation" Concept Explication, International Journal of Environmental and Science Education, 11(18), 11993-12003 (2016) 